University of Nebraska - Lincoln

DigitalCommons@University of Nebraska - Lincoln

USDA Wildlife Services - Staff Publications

U.S. Department of Agriculture: Animal and Plant Health Inspection Service

$10-1-2021$

\title{
Variations, validations, degradations, and noninvasive determination of pregnancy using fecal steroid metabolites in free-ranging pronghorn
}

\author{
Cole A. Bleke \\ Utah State University, cole.bleke@usu.edu \\ Eric M. Gese \\ USDA National Wildlife Research Center, Logan, UT, eric.gese@usu.edu \\ Susannah S. French \\ Utah State University, susannah.french@usu.edu
}

Follow this and additional works at: https://digitalcommons.unl.edu/icwdm_usdanwrc

Part of the Natural Resources and Conservation Commons, Natural Resources Management and Policy Commons, Other Environmental Sciences Commons, Other Veterinary Medicine Commons, Population Biology Commons, Terrestrial and Aquatic Ecology Commons, Veterinary Infectious Diseases Commons, Veterinary Microbiology and Immunobiology Commons, Veterinary Preventive Medicine, Epidemiology, and Public Health Commons, and the Zoology Commons

Bleke, Cole A.; Gese, Eric M.; and French, Susannah S., "Variations, validations, degradations, and noninvasive determination of pregnancy using fecal steroid metabolites in free-ranging pronghorn" (2021). USDA Wildlife Services - Staff Publications. 2473.

https://digitalcommons.unl.edu/icwdm_usdanwrc/2473

This Article is brought to you for free and open access by the U.S. Department of Agriculture: Animal and Plant Health Inspection Service at DigitalCommons@University of Nebraska - Lincoln. It has been accepted for inclusion in USDA Wildlife Services - Staff Publications by an authorized administrator of DigitalCommons@University of Nebraska - Lincoln. 
Research paper

\title{
Variations, validations, degradations, and noninvasive determination of pregnancy using fecal steroid metabolites in free-ranging pronghorn
}

\author{
Cole A. Bleke ${ }^{a, *}$, Eric M. Gese ${ }^{b}$, Susannah S. French ${ }^{c}$ \\ ${ }^{a}$ Department of Wildland Resources, Utah State University, Logan, UT 84322, USA \\ ${ }^{\mathrm{b}}$ U.S. Department of Agriculture-Wildlife Services-National Wildlife Research Center, Department of Wildland Resources, Utah State University, Logan, UT 84322, USA \\ ${ }^{\mathrm{c}}$ Department of Biology and the Ecology Center, Utah State University, Logan, UT 84322, USA
}

\section{A R T I C L E I N F O}

\section{Keywords:}

Antilocapra americana

Degradation

Fecal hormone

Pregnancy

Pronghorn

\begin{abstract}
A B S T R A C T
Pregnancy status is a key parameter used to assess reproductive performance of a species as it represents a starting point for measuring vital rates. Vital rates allow managers to determine trends in populations such as neonate survival and recruitment; two important factors in ungulate population growth rates. Techniques to determine pregnancy have generally involved capture and restraint of the animal to obtain blood samples for determining serum hormone levels. Non-invasive pregnancy assessment, via feces, eliminates any hazards between handler and animal, as well as removes handling-induced physiological biases. Using noninvasive fecal sampling, we conducted hormone validations, investigated pregnancy rates, and determined hormone degradation rates across five subpopulations of pronghorn (Antilocapra americana) in Idaho. Samples were collected during April-May of 2018 and 2019 from adult pronghorn of known sex and age class. Metabolites of testosterone, cortisol, $17 \beta$-estradiol, and progesterone were measured in fecal samples, and concentrations of estradiol and progesterone were examined for pregnancy determination. Average fecal progesterone metabolite (FPM) levels of pregnant females were more than double compared to levels of nonpregnant females. Fecal estrogen metabolite (FEM) levels did not differ during concurrent sampling. The largest difference in FPM levels between pregnant and nonpregnant females began on 28 April. Pregnancy determination sampling showed average FPM levels for all five subpopulations were significantly different than the nonpregnant female validation group. Nonetheless, pregnancy rates for some subpopulations lacked conclusive estimates due to early fecal sampling. Fecal glucocorticoid metabolites (FGM) levels significantly differed between pregnant females and male pronghorn, but did not differ from nonpregnant females. Degradation rates of FPM and FGM differed across days, with values for FPM from Day 1 being significantly different from all subsequent days, and after Day 9 for FGM, demonstrating the requirement of fresh samples to accurately measure hormone concentrations. We concluded that a noninvasive method to diagnosis pregnancy is possible in pronghorn via progesterone metabolites if fresh samples are collected during late gestation.
\end{abstract}

\section{Introduction}

Pronghorn antelope are an iconic wildlife species of sagebrush (Artemisia spp.) and grassland ecosystems in western North America (Reinking et al., 2018). Pronghorn have the unique distinction among mammals to be the only members of the order Antilocapridae and Genus Antilocapra (Harveson, 2006). Current distribution of pronghorn is but a fraction of their historic range (Yoakum, 2004), prompting research into techniques for monitoring population status. Monitoring population vital rates (i.e., pregnancy, litter size, fetal and juvenile survival) allows managers to estimate trends in population growth rates, as well as mechanistic relationships between environmental factors and specific vital rates of population demography (Todd and Rothermel, 2006; DeCesare et al., 2012).

The general health and stability of a population reflects its capacity to reproduce, given that decreased reproduction is usually the first physiological loss that may result from severe stress (Lasley and Kirkpatrick, 1991). Pregnancy status is a key parameter commonly used to assess reproductive performance because, following ovulation, it represents a starting point for succeeding measurements of vital rates, including neonatal survival, and recruitment of individuals into a population (Ramsay and Sadlier, 1979; Messier et al., 1990; Kirkpatrick

\footnotetext{
* Corresponding author.

E-mail addresses: cole.bleke@usu.edu (C.A. Bleke), eric.gese@usu.edu (E.M. Gese), susannah.french@usu.edu (S.S. French).
} 
et al., 1993; Russell et al., 1998; Stoops et al., 1999; Cain et al., 2012). The most important factor in pronghorn population growth is generally considered to be fawn survival and recruitment ( $\mathrm{O}^{\prime}$ Gara and Shaw, 2004).

Determining pregnancy in wild ungulates is inherently difficult and presents a serious challenge to researchers interested in reproduction in free-ranging animals (Cain et al., 2012). Generally, techniques used to directly assess pregnancy in individuals has involved capture and restraint of the animal. There are hazards associated with handling animals, some of which may bias the results of intended research (Welsh and Johnson, 1981; Cain et al., 2012). Hormone monitoring was originally developed in zoos where the reproductive biology of captive animals could be evaluated through excretion profiles of gonadal steroid metabolites. Captive animal studies allowed for longitudinal characterization of reproductive cycles, monitoring of treatment therapies, and provided insight into the mechanisms associated with hormones, behavior, and seasonality (Lasley and Kirkpatrick, 1991).

Given that successful management of wildlife requires the understanding of reproductive biology, techniques can be extended from captive to wild, free-range settings (Lasley and Kirkpatrick, 1991). Development of noninvasive techniques for assessing pregnancy in uncaptured ungulates is an active area of research that promises to provide biologists and managers with a new and useful tool for the study of reproduction without risk to the animal (Messier et al., 1990). The ability to collect noninvasive, repetitive biological samples containing physiological information makes urine and fecal sampling superior to invasive methods which may compromise the physiological state of wild animals (Stoops et al., 1999). During pregnancy in most mammals, estradiol and progesterone are produced by the placenta and ovaries (Messier et al., 1990) and are excreted in feces (Desaulniers et al., 1989). Therefore, estradiol or progesterone metabolite concentrations can be measured to assess the pregnancy status of animals (Lasley, 1985). Repetitive sampling has proven unnecessary for pregnancy assessment (Garrott et al., 1998; Linklater et al., 2000; Schoenecker et al., 2004). More importantly, the timing of fecal collections, in relation to parturition, is critical to ensuring single sample efficiency (Garrott et al., 1998; Schoenecker et al., 2004).

Analysis of fecal steroid concentrations has been used to determine pregnancy in several wild ungulate species, including caribou (Rangifer tarandus; Messier et al., 1990), elk (Cervus canadensis; White et al., 1995; Garrott et al., 1998; Stoops et al., 1999), and bison (Bison bison; Cain et al., 2012). Previous techniques used for determining pregnancy in pronghorn included transrectal ultrasound (Canon et al., 1997) and serum progesterone (O'Gara, 2004). These methods involved handling and physical restraint of the animal, which presented potential hazards to both the animal (Peterson et al., 2003) and the handler (Jessup et al., 1988). Pronghorn are especially sensitive to stress and mortality from capture (Kreeger et al., 2002), thus, alternative methods, such as noninvasive sampling are appealing (Woodruff et al., 2016). Steroid concentrations in feces reflect an integrated average of those found in plasma, but have a lag time, that depending on the species, ranged from $12 \mathrm{~h}$ to greater than 2 days compared to the immediate snapshot of plasma concentrations. (Schwarzenberger et al., 1996; Sheriff et al., 2011).

Sex, reproductive status, and age of an animal influence glucocorticoid production (Romero, 2002). In mammals, these glucocorticoids are linked with suppressive effects on male and female reproduction. These affects impact males and females differently, but broadly can affect ovulation and uterine maturation in females and hormone production in males (Wingfield and Sapolsky, 2003). Reproduction, particularly in the female, is a highly costly anabolic state (Sapolsky et al., 2000). Females experience elevated cortisol levels from middle to late gestation, parallel with progesterone, and sharply decline following parturition to levels that are still greater than males or nonpregnant females (Atkinson and Waddell, 1995). This increase in cortisol into late gestation is thought to assist in multiple aspects of female survival and natal development; including, decreased cortisol sensitivity to protect the developing fetus (Reeder and Kramer, 2005), increased fat stores to support lactation, promote contraction of the uterus, expulsion of the fetus, and rejection of the placenta (Mor et al., 2011; Shi et al., 2021). Iteroparous males tend to have higher basal and stress-induced cortisol levels than females during the breeding season (Boonstra et al., 2001), when testosterone levels are also elevated, which is likely the result of territory establishment, male-male competition and any dominance interactions (Creel, 2001, 2005), compared to the nonbreeding season.

Our overall goal of this study was to evaluate noninvasive fecal sampling to determine pregnancy rates in pronghorn and document the natural variation in fecal hormone metabolites when collected from a wild, free-ranging ungulate population. The objectives of this study were to first, understand and validate natural differences in fecal sex steroid metabolites among pregnant and nonpregnant females and male pronghorn, and determine the viability of fecal steroid metabolites as a means of detecting pregnancy, as well as how these levels vary spatially (i.e., among different subpopulations) and over time (i.e., across the reproductive season). Second, evaluate the use of visual diagnosis of pregnancy to associated fecal hormone metabolites. Third, document pregnancy rates of female pronghorn across five subpopulations, and lastly, determine degradation rates of fecal steroid hormones for pronghorn.

Our first hypothesis was that fecal progesterone metabolites (FPM) would accurately reflect pregnancy status, and thus we predicted that FPMs would significantly differ in pregnant females compared to nonpregnant females. Our second hypothesis was that FGM concentrations would be significantly different in pregnant females compared to nonpregnant females and males due to the internal processes of pregnancy. As such, we predicted a larger variance of FGM concentrations in pregnant females compared to nonpregnant females and males, given the physiological implications of gestation, and that timing of sample collection occurred at varying gestational stages across all subpopulations. Further, we predicted pregnancy rates among adult female pronghorn would be consistent across the five subpopulations samples. Lastly, we predicted fecal hormone metabolites, from female pronghorn, would decrease in feces with prolonged exposure to the elements as part of our fecal hormone degradation study.

\section{Material and methods}

\subsection{Study area}

This study was conducted within five pronghorn subpopulations throughout southern and southeastern Idaho that represent the breadth of habitat types and pronghorn population productivity in the state (Fig. 1; Smyser, 2008). Study subpopulations included; Jarbidge, Camas Prairie, Little Wood, Birch Creek, and Pahsimeroi. The Jarbidge study site has a resident pronghorn subpopulation occupying desert habitat. Based on Idaho's GAP analysis land cover classification (Scott et al. 2002), basin and Wyoming big sagebrush (Artemisia tridentata tridentata and $A$. $t$. wyomingensis) are the dominant cover types. Perennial grasses (i.e., crested wheatgrass [Agropyron cristatum]) were the next most dominant cover type; with the remaining landscape being a mix of low sagebrush (Artemesia arbuscula), antelope bitterbrush (Purshia tridentata), and rabbit brush (Chrysothamnus spp.) communities. The Camas Prairie study site has a migratory pronghorn subpopulation persisting largely on agricultural lands through the summer months. Alfalfa (Medicago sativa) is the dominant crop followed by barley (Hordeum vulgare) and grass hay, pasture, and conservation reserve program (CRP) lands (Kinder 2004). Perennial grasses and basin and Wyoming big sagebrush communities persist on the BLM and state lands in the study site. The Little Wood study site has a migratory pronghorn subpopulation occupying native shrub-steppe rangelands. Basin and Wyoming big sagebrush are the dominant vegetation type. Agricultural land accounts for the next largest habitat type with irrigated alfalfa 


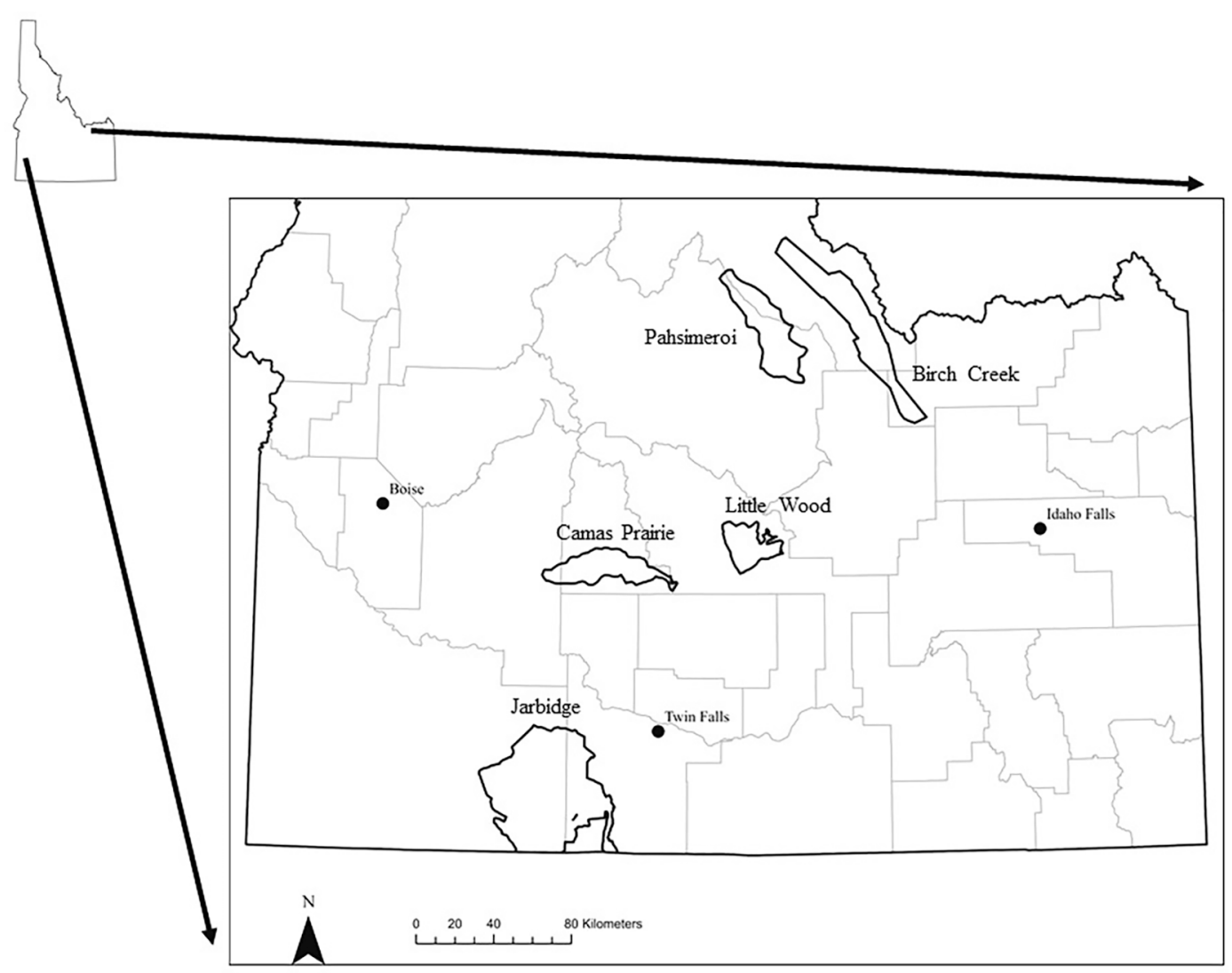

Fig. 1. Study subpopulations within the state of Idaho were geographically disjunct through the pre-migration sampling period. Study subpopulations were selected to represent the breadth of habitats occupied by pronghorn in Idaho. Grey lines represent county boundaries.

being the primary crop. The remainder of the study area consists of mountain big sagebrush (A. t. vaseyana), perennial grasslands, and antelope bitterbrush. Birch Creek and Pahsimeroi study sites represent migratory subpopulations inhabiting mountain valley habitats. Low sagebrush is the dominant vegetation community within the Birch Creek site while mountain, basin, and Wyoming big sagebrush account for a large portion of the study site with limited agricultural lands. The Pahsimeroi subpopulation occupies both the Pahsimeroi and Little lost valleys where mixed stands of mountain big sagebrush and low sagebrush dominate much of the landscape. Basin and Wyoming big sagebrush are the next most abundant cover types and agricultural lands account for less than within the Birch Creek site (Smyser 2008). Greater detail of these study sites is available (Smyser 2008).

\subsection{Reproductive status}

We required known individuals for sample collection in order to validate FPM and fecal estrogen metabolites (FEM) concentrations associated with pregnancy, which we separated into two designated classes: "visibly pregnant" and "visibly nonpregnant" females. Pronghorn reach sexual maturity at 16-17 months of age (O'Gara, 2004) meaning any individual older than a yearling located in this study was classified as an adult. Pronghorn, bearing twins, invest more in reproduction than all other ungulate species per reproductive event (Robbins and Robbins, 1979; Byers and Moodie, 1990), expending considerable energetic reserves during prenatal and postnatal phases of offspring development (Robbins and Robbins, 1979; Byers, 1997; O'Gara, 2004). Pronghorn gestation is longer than other ungulates of a similar size (O'Gara, 2004; Reinking et al., 2018), and the combined weight of pronghorn offspring at birth is about $15.5 \%$ of maternal weight, making the ratio of offspring to adult female weight higher than all other ungulates (Robbins and Robbins, 1979). Roughly $80 \%$ of pronghorn fetal mass development occurs in the final 50 days of gestation (Robbins and Robbins, 1979; Barnowe-Meyer et al., 2011). We feel these facts provide evidence for visual diagnosis of pregnancy in pronghorn during late gestation.

For the validation study, we defined "visibly pregnant" (hereby referred to as pregnant) as adult females, at least 2 years old, with a distinct ventral drop of the abdomen, posterior to the sternum (Fig. 2). The unique appearance of a distended abdomen in pregnant pronghorn females has been noted prior (Bromley, 1977). Females lacking the ventral drop were defined as "visibly nonpregnant" (hereby referred to as nonpregnant), and this group was comprised mostly of yearling

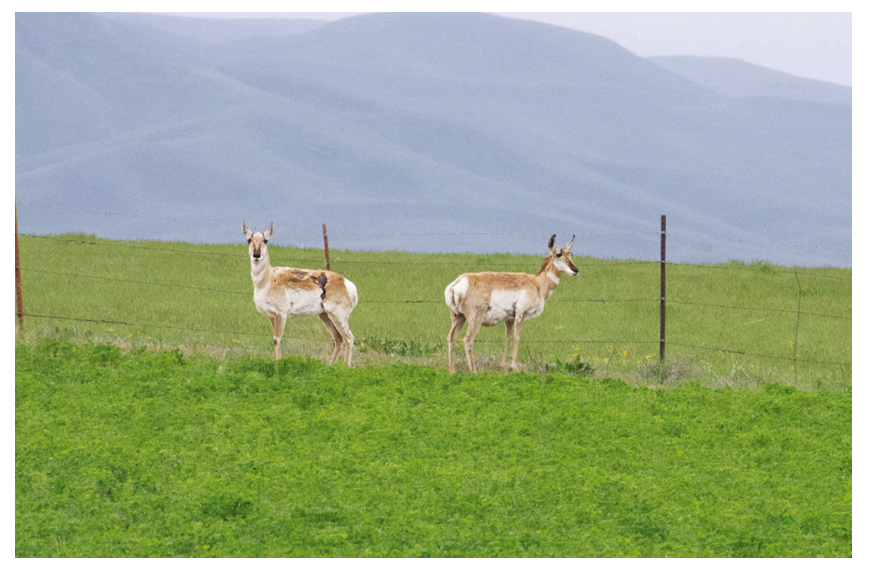

Fig. 2. Visually-diagnosed differences of pregnant and nonpregnant female pronghorn. Pregnant individual on the right has ventral drop compared to the flat abdomen of nonpregnant individual on the left (photo taken mid-May 2019 by Justin Leegard). 
females. This distinction was necessary to ensure proper determination of pregnancy. Given the objective of this study, we employed a conservative approach when visually diagnosing pregnancy and targeted sexually immature females (e.g., yearlings) so as not to bias results. We recognized that using this criterion invited some potential for falsely classifying pregnancy status, particularly in the nonpregnant group, but this was unavoidable considering no animals were marked in this study.

\subsection{Sample collections}

We collected fresh fecal samples from reproductive-aged female pronghorn (i.e., 2 years and older) during late gestation (April to midMay) in 2018 and 2019 for species and hormone validations, to investigate pregnancy rates, and to determine hormone degradation rates. Sample timing was due to two factors; unknown dates outside of a 4week window we were presented with, given the assumption that all subpopulations fawned in that window, and ample time to ensure sample sizes were met per subpopulation prior to parturition. Fecal collections involved using magnifying optics to identify individuals in the field to age class, sex, and pregnancy status (only for validation samples), and, once defecation occurred, used 2-person teams with twoway radio communication to locate pellet piles. Collections occurred within minutes following defecation. All fecal samples were labelled with the date, subpopulation, UTM coordinates, age class, sex, and identification number on the outside of the Whirl-Pak ${ }^{\circledR}$ (Nasco, Inc.). Ensuing collection and labelling, samples were stored in an airconditioned vehicle, out of direct sunlight, until they could be frozen. Average time between collection and freezing of samples was five hours.

Freezing fecal samples soon after collection is a valuable method for preserving FPM (Galama et al., 2004; Peter et al., 2018) as well as FGM (Hunt and Wasser, 2003) and varying amounts of time between collection and storage has shown mixed effects on fecal hormone metabolite concentrations (Möstl et al., 1999; Barja et al., 2012). Fecal samples used for hormone analyses are sometimes stored in preservatives prior to freezing, but these treatments could influence the structure and immunoreactivity of FGMs in particular (Millspaugh and Washburn, 2004). Millspaugh and Washburn (2004) recommended freezing samples as soon as possible, without any chemical treatment, to slow microbial activity and reduce problems with immunoreactivity. Our samples were thawed only once prior to extractions, as thawing and warming has been noted to continue fecal hormone metabolism (Millspaugh et al., 2003; Möstl et al., 2005), and extractions commenced following sample thawing.

We collected a total of 82 fecal samples for validation of sex steroid hormone concentrations. Of these, 72 samples were used for pregnancy validations with 42 collected from pregnant females and 30 from nonpregnant females. The remaining 10 samples were collected from males to be used for male hormone validations. We collected 350 fresh samples from adults for subpopulation pregnancy rate determination during the same period with 50 samples each from the Camas Prairie, Jarbidge, and Little Wood subpopulations, and 100 samples each from Birch Creek and Pahsimeroi subpopulations. If we were uncertain whether an individual female pronghorn was sexually mature, we did not collect a sample. This included individuals by themselves that lacked a reference for age or size, or individuals perceived to be yearlings based on overall body size.

We initiated a fecal hormone degradation study for FPM and FGM levels in pronghorn to test the rate at which naturally occurring bacteria and bacterial enzymes in feces decompose steroid metabolites following defecation (Möstl et al., 1999; Wasser et al., 1988). This study was developed for the benefit of wildlife managers to both understand the potential utility and interpretation of collecting older fecal samples at the scale of days rather than hours. Fecal collections for this experiment were separate from other samples. We located 12 additional pregnant females on 25 April, 9 May, and 10 May 2018, collected three pellets to constitute as our "Day 1" sample, and gathered the remainder of the fresh pellet pile separately. The three pellets were placed into a small Whirl-Pak ${ }^{\circledR}$ (Nasco, Inc.) and labelled it as the "Day 1" sample, while the remainder of the pellets from the same pile were amassed into a separate large Whirl-Pak ${ }^{\circledR}$. Field situations and staggered sample collections were not conducive for immediate start to degradation study so all samples were frozen until field work was completed. We considered this initial freeze to be equivalent to an overnight freeze in the spring; however, if there are any negative impacts of freezing on hormone detection, each sample should be affected similarly since we standardized freezing of all samples. Rapid freezing of fecal samples is optimal we did not exceed the advised freezing duration of 90-120 days (Khan et al., 2002).

Samples from the large Whirl-Pak ${ }^{\circledR}$ were thawed and exposed to ambient conditions for 40 days from 16 July to 23 August 2018 at the U. S. Department of Agriculture, Wildlife Services, National Wildlife Research Center, Predator Research Facility, near Millville, Utah. To ensure samples were kept separate, we used a wood pallet similar to Woodruff et al. (2014). We collected 1-2 pellets from each sample at days $3,5,7,11,14,20,25,30,35$, and 40 , post re-exposure, to measure degradation rates over time. We chose this sampling interval to track the stability of these fecal hormone metabolites, but also for the interpretation and application of results as aging of fecal pellets at the scale of hours is more difficult to identify than that of days. We placed pellets in a Whirl-Pak ${ }^{\circledR}$, labelled with date, sample ID, day, and froze each sample until extractions could be run. In addition, we tracked precipitation, temperature, and maximum percent humidity (based on one-hour time stamps) during this period from the Logan-Cache airport weather station (www.wunderground.com). Average high temperature during this period was $33^{\circ} \mathrm{C}$ with a low of $14^{\circ} \mathrm{C}$. Precipitation total was $1.24 \mathrm{~cm}$.

\subsection{Fecal extractions}

We extracted steroid metabolites from fecal samples using a phosphate and methanol wet extraction buffer (Shideler et al., 1993), but modified to increase yields of estradiol, progesterone, and testosterone from feces (Bauman and Hardin, 1998). The modification involved increasing final methanol concentration from $20 \%$ to $50 \%$ and adding sodium azide to inhibit bacterial growth (Bauman and Hardin, 1998). We weighed $20 \mathrm{~mL}$ scintillation vials (Wheaton, Milville, NJ, USA) prior to use, with the lids off to constitute the initial weight. Each fecal sample was thawed, weighed to $0.50 \pm 0.01 \mathrm{~g}$ wet feces, added to a labelled vial, and inundated with $5.0 \mathrm{~mL}$ of working fecal extraction buffer (50:50 buffer:methanol). Using a clean spatula, we broke up the fecal to incorporate the buffer and vortexed for $20 \mathrm{~s}$. Vials were placed on a shaker at $200 \mathrm{rpm}$ for a minimum of $16 \mathrm{~h}$. The liquid was decanted into $12 \times 75 \mathrm{~mm}$ glass tubes (Fisherbrand, Ontario, Canada) after the vials were allowed to settle for an hour. Following the decanting, the tubes were centrifuged for an hour at $3,500 \mathrm{rpm}$ at $4{ }^{\circ} \mathrm{C}$ (Beckman Coulter Allegra $^{\mathrm{TM}}$ 6R Centrifuge, Indianapolis, IN, USA). Tubes were decanted again into clean $1.5 \mathrm{~mL}$ microcentrifuge tubes (Fisherbrand) and stored at $-80{ }^{\circ} \mathrm{C}$. The remaining fecal in the glass tubes was poured back into original scintillation vials and placed in a drying oven until all moisture was evaporated. Vials were weighed a second time constituting the sample's final weight to standardize hormone concentrations based on fecal weight per sample.

\subsection{Enzyme-Linked Immunoassays}

We measured steroid hormones using enzyme-linked immunosorbent assay kits (ELISA, Enzo Life Sciences, Inc., Farmingdale, NY, USA) following the manufacturer's protocol for testosterone, 17 $\beta$-estradiol, cortisol, and progesterone, and optimized for pronghorn. Assay kits are designed for the quantitative determination of hormone in biological fluid. The testosterone, cortisol, and progesterone ELISAs are based on competitive binding between mouse monoclonal antibodies and plasma hormone that occurs on a goat anti-mouse immunoglobulin microtiter 
plate. The $17 \beta$-estradiol ELISA is based on competitive binding between sheep polyclonal antibodies and plasma hormone that occurs on a donkey anti-sheep immunoglobulin microtiter plate. We labeled $12 \times$ $75 \mathrm{~mm}$ glass tubes, number dependent on hormone, to generate standard curves. Volumes of assay buffer and hormone standard were dependent upon ELISA kit due to dilution variation (estradiol 1:33; progesterone 1:50; testosterone 1:33; cortisol 1:20). Minimum detectable values were $0.0285 \mathrm{ng} / \mathrm{ml}$ for $17 \beta$-estradiol, $0.00857 \mathrm{ng} / \mathrm{ml}$ for progesterone, $0.00567 \mathrm{ng} / \mathrm{ml}$ for testosterone, and $0.05672 \mathrm{ng} / \mathrm{ml}$ for cortisol. We adjusted the dilution of the sample for individuals whose output failed to befall on the standard curve. A standard curve was run for each assay.

Hormone assay kits varied in number of samples, to be run in duplicates, per plate, 37 for cortisol and $17 \beta$-estradiol, 38 for progesterone, and 39 for testosterone, which were averaged to calculate the resulting concentration for each sample. We pipetted standard dilutions, controls, and zeros (blanks to control for nonspecific binding) onto the plate and added assay buffer. Each plate was incubated at room temperature on a titer plate shaker (Lab-Line Instruments, Inc., Kerala, India) for $2 \mathrm{~h}$ at $500 \mathrm{rpm}$. After shaking, we washed each plate four times with the supplied wash buffer in a plate washer (BioRad, Hercules, CA, USA). Next, we added p-nitrophenyl phosphate (pNpp) substrate solution to every well and incubated, either with or without shaking, for 45-60 min at room temperate, depending on the ELISA kit. Finally, we added stop solution to every well and read the plates immediately using a microplate reader (BioRad), with optical density and corrections dependent on the hormone analysis. Standard curves, controls, and controls for non-specific binding were run on each plate. We displayed standard curves as four-parameter logistic curves.

Immunoassays for measuring fecal hormone metabolite levels need to be validated in a species-specific manner to ensure that the hormone of interest is being properly measured as a metabolite in the feces (Palme, 2005; Touma and Palme, 2005). Due to the novelty of assay use in this species, we completed fecal hormone validations for pronghorn prior to running samples. Validations were established to determine appropriate hormone concentrations, control for assay precision, and detect any potential nonspecific binding that would bias results. We validated fecal glucocorticoid metabolites, progesterone, and $17 \beta$ estradiol metabolites in female and fecal cortisol and testosterone metabolites (FTM) in male pronghorn using the pregnant, nonpregnant, and male samples. First, we determined parallelism for each hormone validation (Supplementary Data SD1). Second, we used an extracted sample from the same individual and generated a spectrum of high to low volumes to associate with the standard curve (Sheriff et al., 2011). We began with using $100 \mu$ of extraction solution and diluting in half until $6.25 \mu$ l. Further dilution was necessary if samples were not on the standard curve. All assay wells during this process were of same individual. Third, we added spikes to calculate recovery to ensure only the hormone of interest was being measured and no binding interference was occurring. The final step was calculating intra- and inter-assay variation which serves as a level of certainty that generated values can be compared with each other. Intra-assay variation was $3.4 \%$ for $17 \beta$ estradiol, and $0.3 \%$ (assay 1) and $8.7 \%$ (assay 2) for cortisol. For testosterone, samples were completed in one assay with an intra-assay variation of $0.1 \%$. Progesterone validation was completed in 7 assays with a mean intra-assay variation of $3.3 \%$ and an inter-assay variation of $17.3 \%$. Samples for pregnancy were run in 11 progesterone assays with a mean intra-assay variation of $4.8 \%$, and inter-assay variation of $22 \%$. Our degradation study was completed in 5 assays for cortisol with a mean intra-assay variation of $4.7 \%$ and an inter-assay variation of $21.6 \%$. Likewise, the mean intra-assay variation over 5 progesterone assays was $3.7 \%$, with an inter-assay variation of $28.7 \%$. Assay spikes and recovery tests, in addition to parallelism curves, were completed for species validations of fecal hormones (Supplementary Data SD1).

\subsection{Data analysis}

Samples were standardized based on dry-weight fecal mass and results were converted from $\mathrm{pg} / \mathrm{mL}$ to $\mathrm{ng} / \mathrm{g}$ of fecal sample. We used standard descriptive statistics to summarize hormone concentration results, and Welch's two sample $t$-test to test for significance between validation means in R (R Development Core Team, 2019). All validation means are reported \pm standard deviation. For pregnancy determination, we used Welch's two sample $t$-test to test for significance between pregnancy sample means and nonpregnant validation group and a oneway analysis of variance (ANOVA) to test for differences among the 5 subpopulation means followed by a Tukey multiple pair-wise comparison test (R Development Core Team, 2019). Means for subpopulations are reported \pm standard error. For the degradation study, we used a repeated-measures ANOVA to test the influence of time on degradations and a pairwise paired $t$-test to test for significant differences between time intervals. P-values were adjusted with the Bonferroni multiple testing correction. We selected the Bonferroni correction because it is the simplest and most conservative approach. An alpha level of 0.05 was set for all statistical tests.

\section{Results}

\subsection{Validation of immunoassay}

We collected ten validation samples each from pregnant and nonpregnant females in 2018 to investigate the appropriate fecal sex steroid hormone (i.e., progesterone or $17 \beta$-estradiol) to use for future pregnancy determination. From these 10 samples, FEM concentrations were not different between pregnant and nonpregnant females $(t=1.71$, $\mathrm{df}=20, \mathrm{p}=0.10$ ) with average concentrations at $2,454.83 \mathrm{ng} / \mathrm{g}$ for pregnant and 1,961.38 ng/g from nonpregnant females, but FPM concentrations were $(\mathrm{t}=2.98, \mathrm{df}=12, \mathrm{p}=0.01 ; \mathrm{Fig}$. 3 ) as pregnant females had a mean concentration of $17,746.81 \mathrm{ng} / \mathrm{g}$ and nonpregnant females had an average FPM concentration of 7,154.01 ng/g, confirming our selection of FPM for this study. In response, we increased sample size to 42 for pregnancy validations by collecting 20 additional samples in 2019 and adding the 12 Day 1 samples from our degradation study. Mean concentrations of FPM from pregnant females remained different from nonpregnant females $(\mathrm{t}=-6.15, \mathrm{df}=62, \mathrm{p}<0.05$ ) with an average concentration of $15,281.78 \mathrm{ng} / \mathrm{g}$ of pregnant females and $6,474.35 \mathrm{ng} / \mathrm{g}$ from nonpregnant females. Differences in mean FPM levels between visually diagnosed pregnant and nonpregnant females, from validation sampling, became significant on 28 April $(t=-4.42$, $d f=5, p<0.05$; Fig. 4) where pregnant females had an average FPM of $16,100.93 \mathrm{ng} / \mathrm{g}$ and the nonpregnant female mean FPM was $6898.06 \mathrm{ng} / \mathrm{g}$. Three pregnant validation samples were removed based on timing of sample collection. Two additional validation samples (one pregnant and one nonpregnant) were removed due to potential sampling bias and assay precision. Males had an average FGM of 7,344.38 ng/g, pregnant female FGM average was 10,111.30 ng/g, and mean FGM for nonpregnant females was $10,251.14 \mathrm{ng} / \mathrm{g}$. Mean concentrations of FGM were not significantly different between pregnant and nonpregnant females $(\mathrm{t}=$ $0.21, \mathrm{df}=45$, p greater than 0.83 ), but were different between pregnant females and males $(t=3.03, \mathrm{df}=44, \mathrm{p}<0.05$; Fig. 3). Mean testosterone metabolite concentrations for males was 3002.19 (ng/g; Table 1). Concentrations, sample sizes, and volume of fecal extract used for each hormone are also reported in Table 1.

\subsection{Pregnancy rates among subpopulations}

Fecal progesterone metabolite concentrations were different between the nonpregnant validation groups and the mean of the 350 subpopulation pregnancy samples ( $\mathrm{p}<0.05$; Table 2). Average FPM of subpopulation pregnancy samples was $16,097.50 \mathrm{ng} / \mathrm{g}$ with a range of $10,576.19$ to $33,793.00 \mathrm{ng} / \mathrm{g}$. Pregnancy rates estimated at the time of 

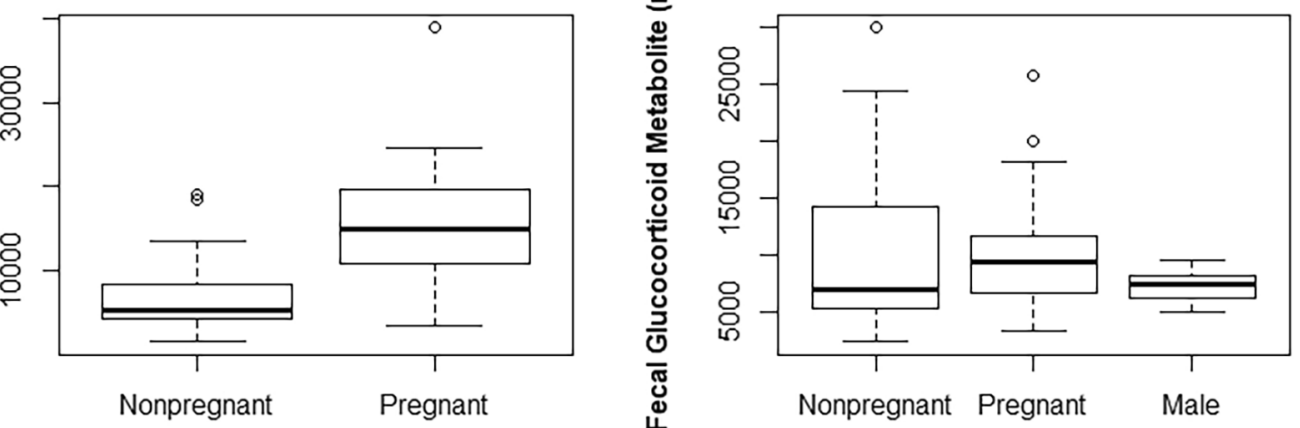

Fig. 3. Average steroid metabolite concentrations $(\mathrm{ng} / \mathrm{g}$ ) of fecal progesterone and fecal glucocorticoid metabolites in fecal samples from nonpregnant females ( $\mathrm{n}=$ 29), pregnant females $(n=38)$, and males $(n=10)$, collected from free-ranging pronghorn.

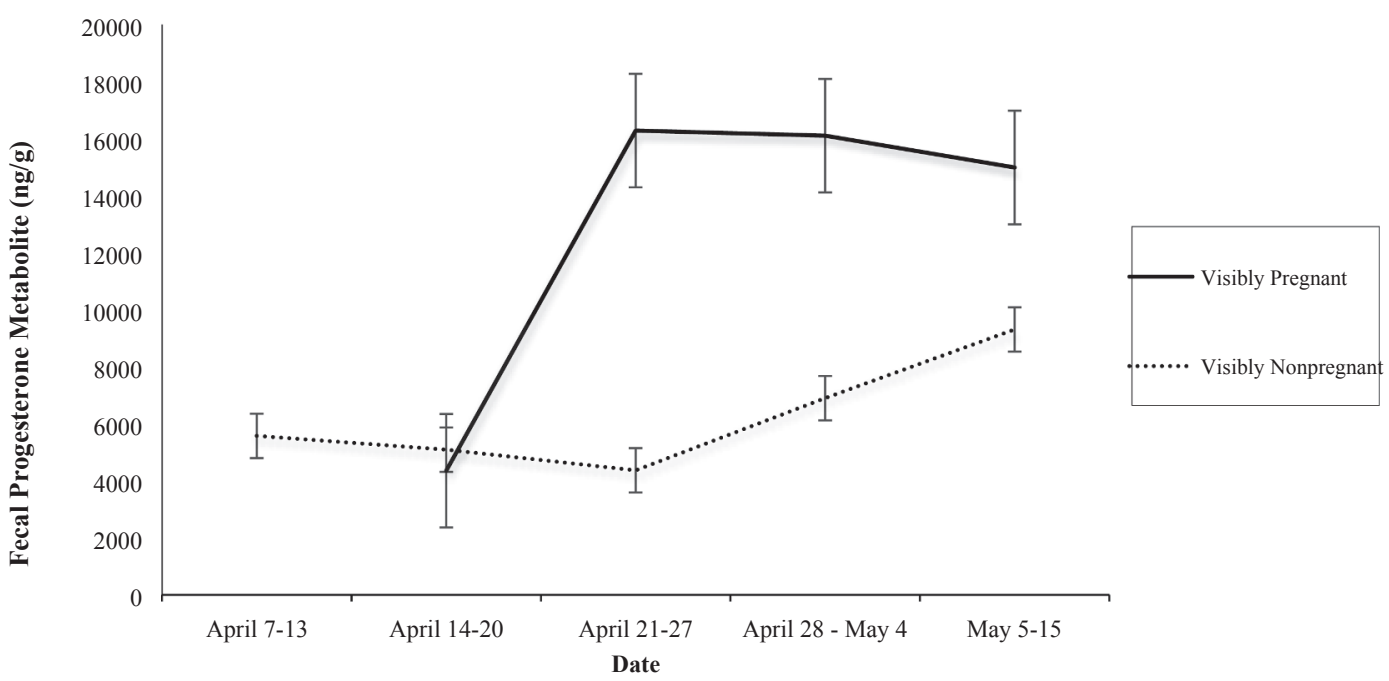

Fig. 4. Distribution of progesterone metabolite concentrations ( $\mathrm{ng} / \mathrm{g})$ in fecal samples collected from nonpregnant females $(\mathrm{n}=29)$ and pregnant females ( $\mathrm{n}=38$ ), collected from free-ranging pronghorn antelope in 2018 and 2019. Timestamps represent averages from independent samples. Sample size varied at each time stamp; April 7-13 (pregnant $=0$, nonpregnant $=5$ ), April 14-20 (pregnant $=5$, nonpregnant $=12$ ), April $21-27$ (pregnant $=21$, nonpregnant $=2$ ), April 28-May 4 (pregnant $=11$, nonpregnant $=5$ ), May 5-15 (pregnant $=11$, nonpregnant $=6$ ).

Table 1

Steroid hormone metabolite concentrations (ng/g) and associated fecal extraction volumes used from pronghorn antelope fecal analyses in 2018 and $2019 . \mathrm{NA}=$ not applicable.

\begin{tabular}{|c|c|c|c|c|c|c|c|c|c|}
\hline & \multicolumn{3}{|c|}{ Pregnant females } & \multicolumn{3}{|c|}{ Nonpregnant females } & \multicolumn{3}{|l|}{ Males } \\
\hline & Mean & SD & $\mathrm{n}$ & Mean & SD & $\mathrm{n}$ & Mean & SD & $\mathrm{n}$ \\
\hline Glucocorticoid metabolite $(5 \mu \mathrm{l})$ & 10111.30 & 4782.11 & 38 & 10251.14 & 7210.87 & 28 & $7344.38^{\mathrm{a}}$ & 1518.10 & 10 \\
\hline Estrogen metabolite $(3 \mu \mathrm{l})$ & 2454.83 & 987.99 & 10 & 1961.38 & 442.29 & 10 & NA & NA & NA \\
\hline Progesterone metabolite $(2 \mu \mathrm{l})$ & $15281.78^{\mathrm{b}}$ & 7193.02 & 38 & 6474.35 & 4471.84 & 28 & NA & NA & NA \\
\hline Testosterone metabolite ( $3 \mu \mathrm{l})$ & NA & NA & NA & NA & NA & NA & 3002.19 & 600.06 & 10 \\
\hline
\end{tabular}

a Steroid hormone metabolite concentration were significantly lower $(\mathrm{p}<0.05)$ in males compared to other classes.

b Steroid hormone metabolite concentration were significantly higher $(\mathrm{p}<0.05)$ in pregnant females compared to other classes.

sampling varied from 50 to $84 \%$ (Table 2). The one-way ANOVA determined a significant difference between subpopulations (FPM: F $(4,345)=23.30, \mathrm{p}<0.05)$ while the Tukey's multiple pairwisecomparisons specified that the Jarbidge subpopulation differed from the remaining subpopulations means ( $\mathrm{p}$ adj $<0.05$ ) by greater than 18,000 ng/g FPM.

\subsection{Fecal hormone degradations}

There was a significant influence of time on concentrations of FPM (days: $\mathrm{F}(3,27)=21.49, \mathrm{p}<0.05$; Fig. 5) and concentrations of FGM (days: $\mathrm{F}(12,120)=5.32, \mathrm{p}<0.05$; Fig. 6). One fecal sample was removed from the study due to low assay precision. Mean Day 1 concentrations for FPM were $17,218.84 \mathrm{ng} / \mathrm{g}$ with a standard deviation of $4,800.58 \mathrm{ng} / \mathrm{g}$. Mean Day 1 concentrations for FGM were 8,299.19 ng/g with a standard deviation of 2,876.99 $\mathrm{ng} / \mathrm{g}$. Degradation of FPM demonstrated a clearer trend than FGM with time (Fig. 6). Differences in FPM means occurred as soon as Day $3(\mathrm{p}<0.05$; $\mathrm{p}$ adj $<0.05)$ as was the same for FGM $(\mathrm{p}<0.05)$, but the Bonferroni multiple testing correction did not detect a difference until Day 9 ( $\mathrm{p}$ adj $<0.05$ ). Both hormones concentrations experienced a $31 \%$ decrease between mean values on Day 1 and Day 3. 
Table 2

Concentration of fecal progesterone metabolites (ng/g) by subpopulation and total from samples for pregnancy determination of pronghorn collected in April and May of 2018 and 2019. ${ }^{\mathrm{a}}$ Fecal progesterone metabolite concentration significantly higher $(\mathrm{p}<0.05)$ than other subpopulations.

\begin{tabular}{|c|c|c|c|c|c|}
\hline Subpopulation & $\begin{array}{l}\text { Fecal } \\
\text { Progesterone } \\
\text { metabolite }\end{array}$ & SE & $\mathrm{N}$ & $\begin{array}{l}\text { Date } \\
\text { Collected }\end{array}$ & $\begin{array}{l}\text { Estimated } \\
\text { Pregnant } \\
(\%)\end{array}$ \\
\hline Jarbidge & $33793.00^{\mathrm{a}}$ & 3381.09 & 50 & 4-8 April & 84.00 \\
\hline Birch Creek & 10576.19 & 1057.62 & 100 & $\begin{array}{l}\text { 10-19 } \\
\text { April }\end{array}$ & 50.00 \\
\hline Pahsimeroi & 14661.47 & 1466.15 & 100 & $\begin{array}{l}21-24 \\
\text { April }\end{array}$ & 83.00 \\
\hline Camas Prairie & 15751.94 & 2453.45 & 50 & $\begin{array}{l}10-16 \\
\text { May }\end{array}$ & 58.00 \\
\hline Little Wood & 12838.34 & 1967.93 & 50 & $\begin{array}{l}28-30 \\
\text { April }\end{array}$ & 56.00 \\
\hline Total & 16097.50 & 867.46 & 350 & & \\
\hline
\end{tabular}

\section{Discussion}

\subsection{Validity of immunoassay}

Overall, we demonstrated that fecal progesterone metabolites accurately reflect pregnancy status and that single-sample pregnancy diagnoses can be accomplished with noninvasive fecal sampling of pronghorn antelope. The concentration of progesterone metabolites in feces provided a reliable indicator of pregnancy in pronghorn antelope.
Fecal progesterone metabolite levels varied longitudinally and increased throughout gestation in free-ranging pronghorn. Conversely, fecal estrogen and fecal glucocorticoid metabolites were not significantly different between pregnant and nonpregnant females at the time of sampling. Our sampling design allowed for the control of bias brought on by age, sex, reproductive condition, and sample age, and their influence on hormone levels.

Progesterone fecal metabolites were significantly higher in pregnant females compared to nonpregnant females. Fecal estrogen metabolite levels were not significantly different. Progesterone and estrogen are cyclic in nature making collection timing important for hormone choice and interpretation of pregnancy status (Plotka et al., 1977b). Estrogen levels increase leading up to parturition from as early as at the time of parturition (Robertson, 1974) to one week prior (Plotka et al., 1977a), to within the last trimester of pregnancy (Messier et al., 1990), depending upon the species. Kersey et al. (2015), using captive peninsular pronghorn (A. a. peninsularis), monitored fecal estrogen and progestagen metabolites from breeding season through parturition. Results from this study found a significant increase in FPM during the third trimester when compared to the first and second, but no difference between first and second trimesters. Fecal estrogen levels increased roughly 30 days prior to parturition through 64 days post parturition (Kersey et al., 2015). Our field-based, single sample study design prevented us from tracking individual pronghorn through gestation. We did not capture increases in FEM which was likely due to small sampling window and sample size. Progesterone is responsible for the establishment and maintenance of pregnancy and tends to remain stable, and even

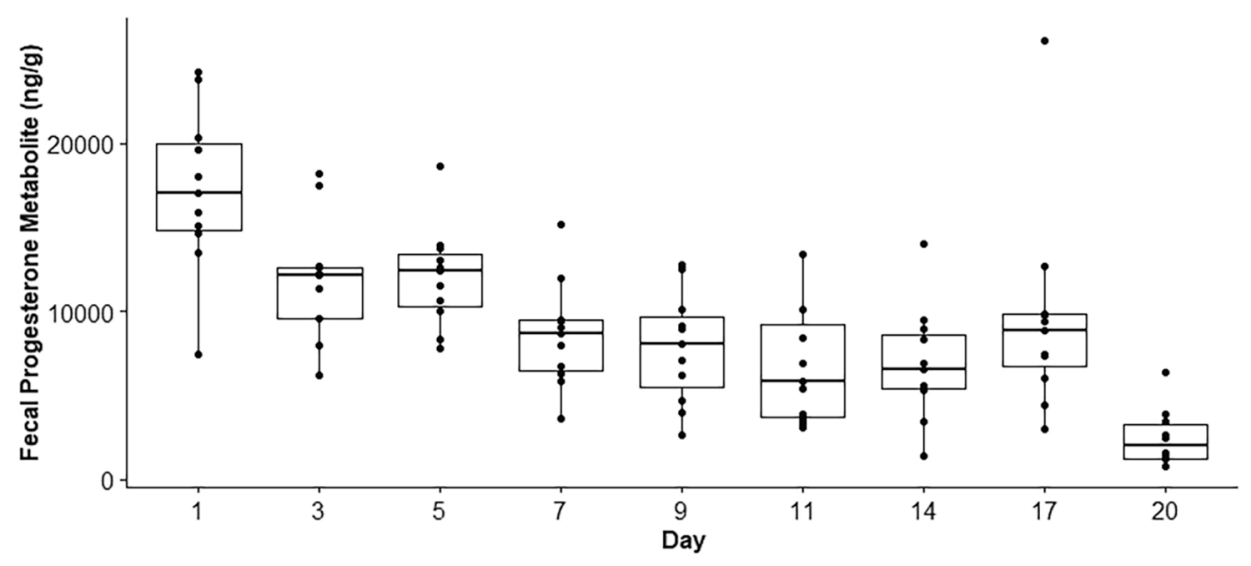

Fig. 5. Degradations of fecal progesterone metabolite concentrations from fecal samples from pregnant female pronghorn $(\mathrm{n}=11)$ collected in 2018. Box plots represent the mean and standard deviation.

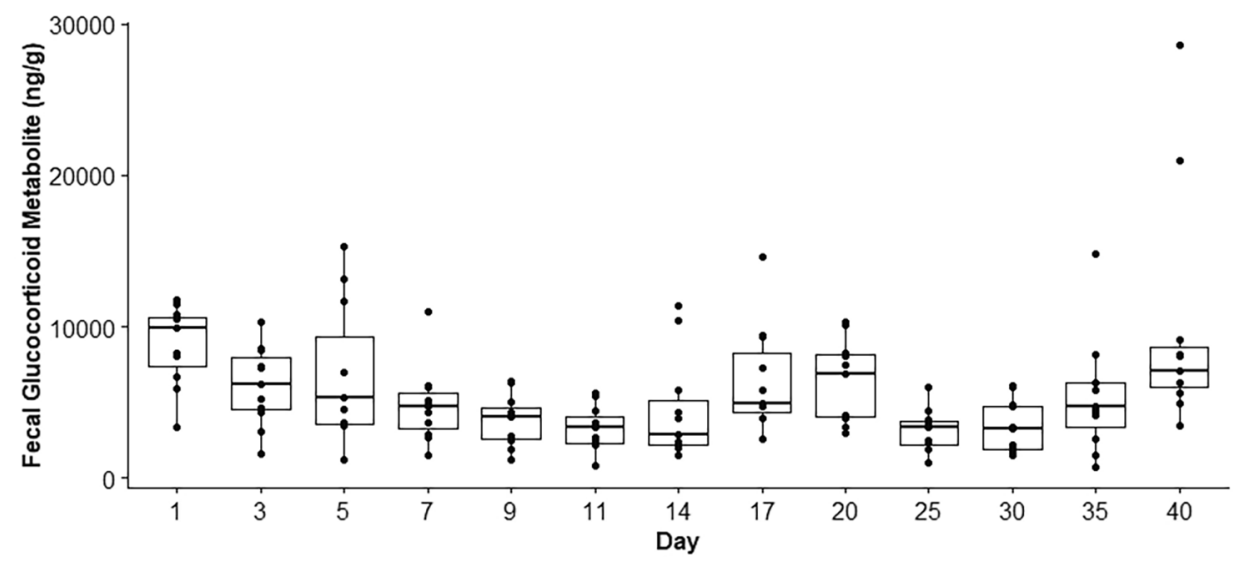

Fig. 6. Degradations of fecal glucocorticoid metabolites concentrations from fecal samples from pregnant female pronghorn $(\mathrm{n}=11)$ collected in 2018. Box plots represent the mean and standard deviation. 
increase, during much of the gestation period (Short, 1958; Stabenfeldt et al., 1970; Irving et al., 1972; Weber et al., 1982; Plotka et al., 1977b). In fact, progesterone has been a reliable indicator of pregnancy as early as day 50 in caribou (Messier et al., 1990), from within the first trimester through parturition in Tule elk (Cervus canadensis nannodes; Stoops et al., 1999) and confirmed as an effective one-sample pregnancy diagnosis (Garrott et al., 1998). Superovulation, or the presence of more corpora lutea than fetuses, has been identified in few other mammals (Wislocki and Fawcett, 1949). Although it is unclear why superovulation exists, the additional luteal tissue produced would yield large amounts of progesterone for maintenance of pregnancy throughout the long gestation period of pronghorn (Roseland, 1977). White-tailed deer (Odocoileus virginianus) females carrying multiple fetuses have higher plasma progesterone than those with singletons (Plotka et al., 1977b). Thus, understanding the cyclic nature of hormone relationships with reproductive events (e.g., gestation length and parturition) and physiological mechanisms are important for determining hormone choice to indicate pregnancy.

We tested the effectiveness of non-invasive pregnancy determination of unmarked pronghorn antelope via visual observation and associated fecal hormone concentrations. Our validation longitudinal study identified when best to sample for hormone results that indicate pregnancy. In this case, samples collected from visually diagnosed pregnant females had FPM different from nonpregnant females on or after 28 April. These results are in line with previous studies that noted the importance of late gestation sampling for FPM to assess pregnancy (Cain et al., 2012; Schoenecker et al., 2004). Fetal growth has been shown to prompt a surge in luteal progesterone production within the latter half to third of pregnancy in sheep (Ovis aries; Spencer and Bazer, 2004), okapi (Okapia johnstoni; Schwarzenbergery et al., 1993), giraffe (Giraffa camelopardalis; del Castillo et al., 2005), and captive peninsular pronghorn (Kersey et al., 2015). Validation samples collected prior to 28 April were not different between the two groups. Given the lack of difference between pregnant and nonpregnant female FPM prior to 28 April, it appears to not be possible to diagnose pregnancy by assay of a single sample. The longitudinal study also provided evidence that pronghorn females develop the distended abdomen prior to an FPM concentration that differed from nonpregnant females. All pregnant validation samples were collected from visually diagnosed pregnant females and the uniqueness of maternal expenditure in pronghorn allow for us to confidently state that visual observation is an efficient method of pregnancy diagnosis in pronghorn, following our recommendation of timing. In addition, variation of FPM concentrations decreased with time for pregnant females but remained relatively constant within nonpregnant females. Timing of collection, conception date, and the effect age has on the degree of secretory activity of the various steroidogenic tissues in females (Weber et al., 1982) likely explains the variation in FPM concentrations from pregnant females. Conversely, we did not observe variation in fecal estrogen metabolites, which is likely due to the narrow sampling timeframe. Even though we were confident in our visual distinction between pregnant and nonpregnant females, surveys to produce accurate pregnancy estimates in pronghorn, whether visual or with assay, should be conducted at the end of April in northern latitudes.

Although not a sex steroid, glucocorticoids frequently change with reproduction. In the present study, we tested whether fecal glucocorticoid metabolites differed between sexes and pregnancy status, as has been documented in other species (Romero, 2002; Reeder and Kramer, 2005; Dantzer et al., 2010). Males had lower FGM levels than pregnant females, supporting our hypothesis. Elevated glucocorticoids during pregnancy is due to either the stress of pregnancy, or the need to free up resources to support the reproductive process (Moberg, 1991; Romero, 2004). Nonpregnant females were intermediate between males and pregnant females, but were much more variable in their FGM levels than pregnant females and males. This further confirms sex differences in FGM concentrations during the spring for pronghorn.
Finally, we assessed FTM in male pronghorn. Similar to our FGM results, this portion of our study was conducted to report successful validations, sample volume required, and average concentrations to be available for future research. Results can only be compared when studies use identical methodology. We found levels were relatively similar across individuals. The most likely explanations are a small sample size, samples collected within only two subpopulations (i.e., Birch Creek and Jarbidge), or a narrow sampling window of 11 days. We were not interested in investigating subpopulation differences, but more so reporting values, meaning collections occurred when available. Within this timeframe males are returning to summer range from winter range and prior to any spatial organization. Pronghorn males have demonstrated two types of spatial organization, undefended home ranges or territory establishment and hormones such as testosterone have been correlated with several aspects of this organization (Maher, 2000). Our short sampling window prevented us from drawing any significant conclusions from these results.

\subsection{Subpopulation estimates}

Understanding how natural hormone concentrations vary across populations in space and in time lends important information to environmental influences and natural life history shifts across seasons. We found a significant difference in fecal hormone concentrations across subpopulations. Specifically, the Jarbidge subpopulation had an average FPM concentration significantly higher than the others. We believe fawning dates of all five subpopulations to align with other previouslyreported northern latitude populations of late May to early June (Hepworth and Blunt, 1966; Mitchell, 1967; O'Gara, 1968; Autenrieth and Fichter, 1975). While fawns are typically born within a three-week period (Autenrieth and Fichter, 1975), the majority are dropped within 10 days (O'Gara, 2004). The Jarbidge subpopulation was sampled from during an earlier timeframe than we recommend for pregnancy determination, but our results cannot explain any reasoning for differences across subpopulations.

Our estimated pregnancy rates of $50-84 \%$, across subpopulations, were below previously reported pregnancy rates in pronghorn $(84 \%$, Canon et al., 1997; 94\%, Barnowe-Meyer et al., 2011; 88\%, Hudgens et al., 2016). Although all subpopulations had average FPM concentrations significantly greater than the nonpregnant average, outlier values inflated the average concentration. The Jarbidge and Pahsimeroi study sites were the only subpopulations with comparable pregnancy rates at $84 \%$ and $83 \%$ respectively. The remaining subpopulations had pregnancy rates below $60 \%$. From our validation work, we determined pregnancy determination from fecal hormones was successful for fecal samples collected on or after 28 April. Pregnancy sampling in some subpopulations occurred prior to that date. Those subpopulations were Jarbidge and Birch Creek and we suspect those rates to be inaccurate. Sampling occurred around the appropriate time within the Pahsimeroi subpopulation so we believe that rate to be accurate. Interestingly, sampling within the Camas Prairie and Little Wood subpopulation occurred after our suggested date and pregnancy rates were low. Reasoning for this is unclear and is something we will investigate in the future. We believe the most important conclusion of this portion of the study to be the importance of sample timing, not a subpopulation effect.

Interestingly, we believe to have documented evidence of a delayed or second estrus within one subpopulation (i.e., Birch Creek) when sampling in late June. A female was visually diagnosed as pregnant on 28 June 2019, and visual observation of pregnancy was supported with extremely high FPM concentration (e.g., greater than 56,000 ng/g). Although the likelihood of this is rare, we feel it is important to document the occurrence as timing of birth can affect fawn vulnerability to predation (Fairbanks, 1993). Einarsen (1948) proposed a single estrus period per year based on the belief that multiple estrous cycles during one breeding season would be unlikely due to the amount of energy expended during the rut. Pronghorn females, with rare exceptions, 
copulate once per estrus and year (Kitchen, 1974; Byers and Moodie, 1990; Byers and Hogg, 1995). Those rare exceptions have been documented in captive and wild settings (O'Gara, 1968; Bodie, 1979; Mitchell, 1980; Pojar and Miller, 1984). Delayed or recurrent estrus can be associated with age (Pojar and Miller, 1984), poor nutrition (Fairbanks, 1993), or social status (Byers and Moodie, 1990). Two nonpregnant females, whose samples were collected during the validation portion of the study, had FPM concentrations comparable to pregnant females even though they lacked a distended abdomen. Pronghorn can undergo recurrent estrous (Pojar and Miller 1984). We believe this to be a possible explanation for these results, similar to findings of Plotka et al. (1977a).

\subsection{Fecal hormone degradations}

We demonstrated a time effect on both FPM and FGM levels from degradation samples, signifying that fresh fecal samples are necessary to accurately measure both hormone concentrations in pronghorn. FGM and FPM concentrations both decreased by an average of $31 \%$ from Day 1 to Day 3, but outliers likely prevented the delay in statistical significance in cortisol until Day 9. Classification information such as age and sex can be obtained while observing defecation and is important because the sex of sampled animals must be known for meaningful pregnancy diagnosis (Messier et al., 1990). Additionally, fecal dimensions of yearling pronghorn are indistinguishable from adults (Woodruff et al., 2016).

Interestingly, we observed spikes in FGM concentrations that seemed to follow decreases in FPM levels, most notably around Day 14. This suggests that steroid hormone degradations over time may be leading to cross-reactivity of antibodies; this is especially true for glucocorticoids and progestagens. In order to describe the trends in degradation rates, we must examine the hormones at the molecular level while also factoring in initial FPM concentrations (mean $=17,218.8 \mathrm{ng} / \mathrm{g}$ ). Progesterone, the most biologically potent progestin, can be routinely quantified in blood using any number of specific antisera, which are reported to exhibit little or no cross reactivity with other structurallysimilar steroids found in blood. However, when progesterone is metabolized and excreted, it is rarely excreted in its native form. Rather, progesterone is generally metabolized to numerus structurally-similar steroid molecules, most of which are rather esoteric in strict physiological terms since their structural forms render them biologically impotent (Lasley and Kirkpatrick, 1991; Schwarzenberger et al., 1996). This lack of a trend in fecal glucocorticoid metabolites metabolite degradations has been documented in various studies (Lafferty et al., 2019; Stevenson et al., 2020; Vynne et al., 2011), and may be due to crossreactivity of the antibodies used to detect cortisol with other metabolites being broken down in the feces. Moreover, these findings further suggest the freezing of fresh samples whenever possible (Hulsman et al., 2011; Möstl et al., 1999; Khan et al., 2002; Muehlenbein et al., 2012; Wasser et al., 1988).

Climatic conditions also likely influenced trends in fecal metabolite concentrations and a lack of an increase above initial values. Washburn and Millspaugh (2002) found that simulated rainfall events artificially elevated FGM measurements as it is believed that additional moisture may have provided a growth environment for microbes and detritivores. Our degradation study occurred within the arid shrub steppe biome where $<1.5 \mathrm{~cm}$ of precipitation fell (www.wunderground.com). In addition, our study was conducted in a realistic field setting. Millspaugh and Washburn (2004) suggested further studies of fecal hormone metabolite degradations be conducted with fecal samples exposed to actual climatic conditions and extended longer than 7 days. Results from this study highlight degradation trends at a larger scale than hours within an arid landscape. We also believe these results can be used as a guideline for wildlife managers interested in future pronghorn fecal hormone studies where discrepancies on the age of fecal samples is easier at the scale of days rather than hours.

\section{Conclusion}

We validated a noninvasive method to measure pregnancy in female pronghorn antelope using fecal progesterone metabolites. We also demonstrated that hormone-specific ELISA's (cortisol, progesterone, estradiol, testosterone) can be used to measure and monitor concentrations and longitudinal trends of fecal metabolite concentrations in this species. We specifically found elevations in progesterone metabolites during pregnancy, but also longitudinal variations in these freeranging animals. Variation in subpopulation pregnancy rates may have been caused by sample timing and results from validation work provide a timeframe to calculate more accurate rates. Fecal glucocorticoid metabolites were elevated during pregnancy and differed between sexes. Our degradation study proved that fecal hormone measures for pronghorn require fresh samples. We discussed factors that may influence variation in parturition events seen across subpopulations. We demonstrated that the more background information on a species or subpopulation obtained prior to any reproductive physiology research, the easier it is to address those questions. Given the high maternal investment of pronghorn and the varying pregnancy rate across subpopulations, future work investigating physiological and nutrition factors and their influence on pregnancy should be examined.

\section{CRediT authorship contribution statement}

Cole A. Bleke: Methodology, Validation, Investigation, Data curation, Writing - original draft, Project administration. Eric M. Gese: Conceptualization, Methodology, Resources, Supervision, Project administration, Funding acquisition, Writing - review \& editing. Susannah S. French: Conceptualization, Validation, Resources, Supervision, Project administration, Writing - review \& editing.

\section{Declaration of Competing Interest}

The authors declare that they have no known competing financial interests or personal relationships that could have appeared to influence the work reported in this paper.

\section{Acknowledgements}

Funding and logistical support provided by the Idaho Department of Fish and Game (IDFG), and the U.S. Department of Agriculture (USDA), Wildlife Services, National Wildlife Research Center. We thank P. Webb, L. Magnicheri, A. James, and J. Leegard for their assistance in field collections and lab work; P. A. Terletzky for assistance with statistical analyses; members of the French Lab at Utah State University for laboratory assistance; and various IDFG biologists, S. Roberts most notably, for organizing field logistics, providing subpopulation information, and volunteering to help with sample collections. The findings and conclusions in this publication have not been formally disseminated by the U.S. Department of Agriculture and should not be construed to represent any agency determination or policy.

\section{Appendix A. Supplementary data}

Supplementary data to this article can be found online at https://doi. org/10.1016/j.ygcen.2021.113841.

\section{References}

Atkinson, H.C., Waddell, B.J., 1995. The hypothalamic-pituitary-adrenal axis in rat pregnancy and lactation: circadian variation and interrelationship of plasma adrenocorticotropin and corticosterone. Endocrinology 136 (2), 512-520. https:// doi.org/10.1210/endo.136.2.7835284.

Autenrieth, R.E., Fichter, E., 1975. On the behavior and socialization of pronghorn fawns. Wildl. Mono. 42, 3-111. https://www.jstor.org/stable/3830503. 
Barja, I., Escribano-Ávila, G., Lara-Romero, C., Virgós, E., Rafart, E., 2012. Non-invasive monitoring of adrenocortical activity in European badgers (Meles meles) and effects of sample collection and storage on faecal cortisol metabolite concentrations. Anim. Biol. 62, 419-432. https://doi.org/10.1163/157075612X642914.

Barnowe-Meyer, K.K., White, P.J., Byers, J.A., 2011. Maternal investment by Yellowstone pronghorn following winter habitat deterioration. West. N. Am. Nat. 71 (2), 222-233. https://doi.org/10.3398/064.071.0209.

Bauman, J.E., Hardin, A., 1998. Measurement of steroids in animal feces with commercially available RIA kits intended for use in human serum. J. Clin. Ligand Assay 21, 83.

Bodie, W.L., 1979. Factors affecting pronghorn fawn mortality in central Idaho (Master's thesis). University of Montana, Missoula, MT https://scholarworks.umt.edu/etd/ 6511.

Boonstra, R., Hubbs, A.H., Lacey, E.A., McColl, C.J., 2001. Seasonal changes in glucocorticoid and testosterone concentrations in free-living arctic ground squirrels from the boreal forest of the Yukon. Can. J. Zool. 79 (1), 49-58. https://doi.org/ 10.1139/z00-175.

Bromley, P.T., 1977. Aspects of the behavioural ecology and sociobiology of the pronghorn (Antilocapra americana) (Doctoral dissertation). University of Calgary, Calgary, Alberta https://doi.org/10.11575/PRISM/24317.

Byers, J.A., Moodie, J.D., 1990. Sex-specific maternal investment in pronghorn, and the question of a limit on differential provisioning in ungulates. Behav. Ecol. Sociobiol. 26, 157-164. https://doi.org/10.1007/BF00172082.

Byers, J.A., Hogg, J.T., 1995. Environmental effects on prenatal growth rate in pronghorn and bighorn: further evidence for energy constraint on sex-biased maternal expenditure. Behav. Ecol. 6 (4), 451-457. https://doi.org/10.1093/ beheco/6.4.451.

Byers, J.A., 1997. American pronghorn: social adaptations and the ghosts of predators past. University of Chicago Press, Chicago, Illinois, USA.

Cain, S.L., Higgs, M.D., Roffe, T.J., Monfort, S.L., Berger, J., 2012. Using fecal progestogens and logistic regression to enhance pregnancy detection in wild ungulates: a bison case study. Wildl. Soc. Bull. 36, 631-640. https://doi.org/ 10.1002/wsb.178.

Canon, S.K., Bryant, F.C., Bretzlaff, K.N., Hellman, J.M., 1997. Pronghorn pregnancy diagnosis using trans-rectal ultrasound. Wildl. Soc. Bull. 25, 832-834. https://www. jstor.org/stable/3783731.

Creel, S., 2001. Social dominance and stress hormones. Trends Ecol. Evol. 16 (9), 491-497. https://doi.org/10.1016/S0169-5347(01)02227-3.

Creel, S., 2005. Dominance, aggression, and glucocorticoid levels in social carnivores. J. Mammal. 86 (2), 255-264. https://doi.org/10.1644/BHE-002.1.

Dantzer, B., McAdam, A.G., Palme, R., Fletcher, Q.E., Boutin, S., Humphries, M.M. Boonstra, R., 2010. Fecal glucocorticoid metabolites metabolite levels in freeranging North American red squirrels: Assay validation and the effects of reproductive condition. Gen. Comp. Endocrinol. 167, 279-286. https://doi.org/ 10.1016/j.ygcen.2010.03.024.

DeCesare, N.J., Hebblewhite, M., Bradley, M., Smith, K.G., Hervieux, D., Neufeld, L., 2012. Estimating ungulate recruitment and growth rates using age ratios. J. Wildl. Manage. 76 (1), 144-153. https://doi.org/10.1002/jwmg.v76.110.1002/jwmg.244.

del Castillo, S.M., Bashaw, M.J., Patton, M.L., Rieches, R.R., Bercovitch, F.B., 2005. Fecal steroid analysis of female giraffe (Giraffa camelopardalis) reproductive condition and the impact of endocrine status on daily time budgets. Gen. Comp. Endocrinol 141 (3), 271-281. https://doi.org/10.1016/j.ygcen.2005.01.011.

Desaulniers, D.M., Goff, A.K., Betteridge, K.J., Rowell, J.E., Flood, P.F., 1989. Reproductive hormone concentrations in faeces during the oestrous cycle and pregnancy in cattle (Bos taurus) and muskoxen (Ovibos moschatus). Can. J. Zool. 67 (5), 1148-1154. https://doi.org/10.1139/z89-165.

Einarsen, A.S., 1948. The pronghorn antelope and its management. Monumental Printing Co., Baltimore, Maryland, USA.

Fairbanks, W.S., 1993. Birthdate, birthweight, and survival in pronghorn fawns. J. Mammal. 74 (1), 129-135. https://doi.org/10.2307/1381911.

Galama, W.T., Graham, L.H., Savage, A., 2004. Comparison of fecal storage methods for steroid analysis in black rhinoceroses (Diceros bicornis). Zoo Biol. 23 (4), 291-300. https://doi.org/10.1002/(ISSN)1098-236110.1002/zoo.v23:410.1002/zoo.20017.

Garrott, R.A., Monfort, S.L., White, P.J., Mashburn, K.L., Cook, J.G., 1998. One-sample pregnancy diagnosis in elk using fecal steroid metabolites. J. Wildl. Dis. 34 (1), 126-131. https://doi.org/10.7589/0090-3558-34.1.126.

Harveson, L.A., 2006. Life history and ecology of pronghorn. In: Cearley, K.A., Nelle, S (Eds.), Pronghorn Symposium. Texas Cooperative Extension, College Station, TX, USA, pp. 1-4.

Hepworth, W.G., Blunt, F., 1966. Research findings on Wyoming antelope. Wy. Wildl. 30, 24-29.

Hudgens, B.R., Duquette, J.F., Garcelon, D.K., Brinkman, M.P., 2016. Assessing pronghorn distribution, movements, and habitat use in northeastern California. Annual Report, Arcata, CA, USA.

Hulsman, A., Dalerum, F., Ganswindt, A., Muenscher, S., Bertschinger, H.J., Paris, M., 2011. Non-invasive monitoring of glucocorticoid metabolites in brown hyaena (Hyaena brunnea) feces. Zoo Biol. 30, 451-458. https://doi.org/10.1002/ zoo. 20325.

Hunt, K., Wasser, S., 2003. Effect of long-term preservation methods on fecal glucocorticoid concentrations of grizzly bear and African elephant. Physiol. Biochem. Zool. 76 (6), 918-928. https://doi.org/10.1086/380209.

Irving, G., Jones, D.E., Knifton, A., 1972. Progesterone concentration in the peripheral plasma of pregnant goats. J. Endocrinol. 53, 447-452. https://doi.org/10.1677/ joe. 0.0530447 .
Jessup, D.A., Clark, R.K., Weaver, R.A., Kock, M.D., 1988. The safety and cost effectiveness of net-gun capture of desert bighorn sheep (Ovis canadensis nelson). J. Zoo Anim. Med. 19, 208-213. https://doi.org/10.2307/20094889.

Kersey, D.C., Holland, J., Eng, C., 2015. Reproductive activity in the peninsular pronghorn determined from excreted gonadal steroid metabolites. Zoo Biol. 34, 183-188. https://doi.org/10.1002/zoo.21199.

Khan, M.Z., Altmann, J., Isani, S.S., Yu, J., 2002. A matter of time: evaluating the storage of fecal samples for steroid analysis. Gen. Comp. Endocrinol. 128 (1), 57-64. https:// doi.org/10.1016/S0016-6480(02)00063-1.

Kinder, C.A., 2004. Camas County situation summary. University of Idaho, Camas County Extension Office, Fairfield, Idaho.

Kirkpatrick, J.F., Gudermuth, D.F., Flagan, R.L., McCarthy, J.C., Lasley, B.L., 1993. Remote monitoring of ovulation and pregnancy of Yellowstone bison. J. Wildl. Manage. 57, 407-412. https://doi.org/10.2307/3809441.

Kitchen, D.W., 1974. Social behavior and ecology of the pronghorn. Wildl. Mono. 38, 3-96. https://www.jstor.org/stable/3830497.

Kreeger, T.J., Arnemo, J.M., Raath, J.P., 2002. Handbook of wildlife chemical immobilization. Wildlife Pharmaceutical Inc, Fort Collins, Colorado.

Lafferty, D.J.R., Zimova, M., Clontz, R.L., Hackländer, K., Mills, L.S., 2019. Noninvasive measures of physiological stress are confounded by exposure. Sci. Rep. 9, 19170. https://doi.org/10.1038/s41598-019-55715-5.

Lasley, B.L., Kirkpatrick, J.F., 1991. Monitoring ovarian function in captive and freeranging wildlife by means of urinary and fecal steroids. J. Zoo Wildl. Med. 22, 23-31. https://www.jstor.org/stable/20095115.

Lasley, B.L., 1985. Methods for evaluating reproductive function in exotic species. Adv. Vet. Sci. Comp. Med. 30, 209-228.

Linklater, W.L., Henderson, K.M., Cameron, E.Z., Stafford, K.J., Minot, E.O., 2000. The robustness of faecal steroid determination for pregnancy testing Kaimanawa feral mares under field conditions. N. Z. Vet. J. 48 (4), 93-98. https://doi.org/10.1080/ 00480169.2000 .36172$.

Maher, C.R., 2000. Quantitative variation in ecological and hormonal variables correlates with spatial organization of pronghorn (Antilocapra americana) males. Behav. Ecol. Sociobiol. 47 (5), 327-338. https://doi.org/10.1007/s002650050673.

Messier, F., Desaulniers, D.M., Goff, A.K., Nault, R., Patenaude, R., Crete, M., 1990. Caribou pregnancy diagnosis from immunoreactive progestins and estrogens excreted in feces. J. Wildl. Manage. 54, 279-283. https://doi.org/10.2307/3809042.

Millspaugh, J.J., Washburn, B.E., Milanick, M.A., Slotow, R., van Dyk, G., 2003. Effects of heat and chemical treatments on fecal glucocorticoid measurements: implications for sample transport. Wildl. Soc. Bull. 31, 399-406. https://www.jstor.org/stable/ 3784319.

Millspaugh, J.J., Washburn, B.E., 2004. Use of fecal glucocorticoid metabolite measures in conservation biology research: considerations for application and interpretation. Gen. Comp. Endocrinol. 138 (3), 189-199. https://doi.org/10.1016/j. ygcen.2004.07.002.

Mitchell, G.J., 1967. Minimum breeding age of female pronghorn antelope. J. Mammal. 48, 489-490. https://doi.org/10.2307/1377797.

Mitchell, G.J., 1980. The pronghorn antelope in Alberta. Fish and Wildlife Division and University of Regina, Regina, Saskatchewan, CA, Alberta Department of Lands and Forests.

Moberg, G.P., 1991. How behavioral stress disrupts the endocrine control of reproduction in domestic animals. J. Dairy. Sci. 74 (1), 304-311. https://doi.org/ 10.3168/jds.S0022-0302(91)78174-5.

Möstl, E., Messmann, S., Bagu, E., Robia, C., Palmer, R., 1999. Measurement of glucocorticoid metabolite concentrations in faeces of domestic livestock. J. Vet. Med. A 46, 621-631. https://doi.org 10.1046/j.1439-0442.1999.00256.x/.

Möstl, E., Rettenbacher, S., Palme, R., 2005. Measurement of corticosterone metabolites in birds' droppings: an analytical approach. Ann. N.Y. Acad. Sci. 1046, 17-34. https://doi.org/ 10.1196/annals.1343.004.

Mor, G., Cardenas, I., Abrahams, V., Guller, S., 2011. Inflammation and pregnancy: the role of the immune system at the implantation site. Ann. N. Y. Acad. Sci. 1221, 80-87. https://doi.org/10.1111/j.1749-6632.2010.05938.x.

Muehlenbein, M.P., Ancrenaz, M., Sakong, R., Ambu, L., Prall, S., Fuller, G., Raghanti, M. A., Gursky-Doyen, S., 2012. Ape conservation physiology: fecal glucocorticoid responses in wild Pongo pygmaeus morio following human visitation. PLoS One 7 (3), e33357. https://doi.org/10.1371/journal.pone.003335710.1371/journal. pone.0033357.g00110.1371/journal.pone.0033357.g00210.1371/journal. pone.0033357.g00310.1371/journal.pone.0033357.t001.

O'Gara, B.W., 1968. A study of the reproductive cycle of the female pronghorn (Antilocapra americana) (Doctoral dissertation). University of Montana, Missoula, MT https://scholarworks.umt.edu/etd/9657/.

O'Gara, B.W., 2004. Reproduction. In: O'Gara, B.W., Yoakum, J.D. (Eds.), Pronghorn: Ecology and Management. University Press of Colorado, Colorado, pp. 275-298.

O'Gara, B.W., Shaw, H.G., 2004. Predation. In: O'Gara, B.W., Yoakum, J.D. (Eds.), Pronghorn: Ecology and Management. University Press of Colorado, Colorado, pp. 337-377.

Palme, R., 2005. Measuring fecal steroids: guidelines for practical application. Ann. N. Y. Acad. Sci. 1046, 75-80. https://doi.org/10.1196/annals.1343.007.

Peter, I.D., Haron, A.W., Jesse, F.F.A., Ajat, M., Han, M.H.W., Fitri, W.N., Yahaya, M.S., Alamaary, M.S.M., 2018. Opportunities and challenges associated with fecal progesterone metabolite analysis. Vet World 11, 1466-1472. https://doi.org/10. 14202/vetworld.2018.1466-1472.

Peterson, M.N., Lopez, R.R., Frank, P.A., Peterson, M.J., Silvy, N.J., 2003. Evaluating capture methods for urban white-tailed deer. Wildl. Soc. Bull. 31, 1176-1187. https://www.jstor.org/stable/3784465. 
Plotka, E.D., Schmoller, G.C., Karns, P.D., Keenlyne, K.D., 1977a. Reproductive steroids in the white-tailed deer (Odocoileus virginianus borealis). I. Seasonal changes in the female. Biol. Reprod. 16, 340-343. https://doi.org/10.1095/biolreprod16.3.340.

Plotka, E.D., Seal, U.S., Verme, L.J., Ozoga, J.J., 1977b. Reproductive steroids in the white-tailed deer (Odocoileus virginianus borealis). II. Progesterone and estrogen levels in peripheral plasma during pregnancy. Biol. Reprod. 17, 78-83. https://doi. org/10.1095/biolreprod17.1.78.

Pojar, T.M., Miller, L.L., 1984. Recurrent estrus and cycle lengths in pronghorn. J. Wildl. Manage. 48, 973-979. https://doi.org/10.2307/3801450.

R Development Core Team, 2019. R: a language and environment for statistical computing. R Foundation for Statistical Computing Vienna, Austria.

Ramsay, M.A., Sadlier, R.M.F.S., 1979. Detection of pregnancy in living bighorn sheep by progestin determination. J. Wildl. Manage. 43, 970-973. https://doi.org/10.2307/ 3808284.

Reeder, D.M., Kramer, K.M., 2005. Stress in free-ranging mammals: integrating physiology, ecology, and natural history. J. Mammal. 86 (2), 225-235. https://doi org/10.1644/BHE-003.1.

Reinking, A.K., Smith, K.T., Monteith, K.L., Mong, T.W., Read, M.J., Beck, J.L., 2018. Intrinsic, environmental, and anthropogenic factors related to pronghorn summer mortality. J. Wildl. Manage. 82 (3), 608-617. https://doi.org/10.1002/jwmg. v82.310.1002/jwmg. 21414.

Robbins, C.T., Robbins, B.L., 1979. Fetal and neonatal growth patterns and maternal reproductive effort in ungulates and subungulates. Am. Nat. 114 (1), 101-116. https://doi.org/10.1086/283456.

Robertson, H.A., 1974. Changes in the concentration of unconjugated oestrone, oestradiol- $17 \alpha$ and oestradiol-17 $\beta$ in the maternal plasma of the pregnant cow in the relation to the initiation of parturition and lactation. J. Reprod. Fertil. 36, 1-7. https://doi.org/10.1530/jrf.0.0360001.

Romero, L.M., 2002. Seasonal changes in plasma glucocorticoid concentrations in freeliving vertebrates. Gen. Comp. Endocrinol. 128 (1), 1-24. https://doi.org/10.1016/ S0016-6480(02)00064-3.

Romero, L.M., 2004. Physiological stress in ecology: Lessons from biomedical research. Trends Ecol. Evol. 19 (5), 249-255. https://doi.org/10.1016/j.tree.2004.03.008.

Roseland, K.K., 1977. Morphology of the pronghorn ovary (Antilocapra americana) (M.S thesis). University of Montana, Missoula, MT.

Russell, D.E., Gerhart, K.L., White, R.G., Van De Wetering, D., 1998. Detection of early pregnancy in caribou: Evidence for embryonic mortality. J. Wildl. Manage. 62, 1066-1075. https://doi.org/10.2307/3802559.

Sapolsky, R.M., Romero, L.M., Munck, A.U., 2000. How do glucocorticoids influence stress response? Integrating permissive, suppressive, stimulatory, and preparative actions. Endocr. Rev. 21, 55-89. https://doi.org/10.1210/edrv.21.1.0389.

Schoenecker, K.A., Lyda, R.O., Kirkpatrick, J., 2004. Comparison of three fecal steroid metabolites for pregnancy detection used with single sampling in bighorn sheep (Ovis canadensis). J. Wildl. Dis. 40 (2), 273-281. https://doi.org/10.7589/00903558-40.2.273

Schwarzenbergery, F., Patzl, M., Francke, R., Ochs, A., Buiter, R., Schaftenaar, M., W.D., 1993. Fecal progestogen evaluations to monitor the estrous cycle and pregnancy in the okapi (Okapia johnstoni). Zoo Biol. 12, 549-559. https://doi.org/10.1002/ the okapi (Okapia jo

Schwarzenberger, Franz, Möstl, Erich, Palme, Rupert, Bamberg, Elmar, 1996. Faecal steroid analysis for non-invasive monitoring of reproductive status in farm, wild and zoo animals. Anim. Reprod. Sci. 42 (1-4), 515-526. https://doi.org/10.1016/03784320(96)01561-8.

Scott, J.M., Peterson, C.R., Karl, J.W., Strand, E., Svancara, L.K., Wright, N.M., 2002 A gap analysis of Idaho: final report. Idaho Cooperative Fish and Wildlife Research Unit, Moscow, Idaho.

Sheriff, Michael J., Dantzer, Ben, Delehanty, Brendan, Palme, Rupert, Boonstra, Rudy, 2011. Measuring stress in wildlife: techniques for quantifying glucocorticoids. Oecol 166 (4), 869-887. https://doi.org/10.1007/s00442-011-1943-y.

Shi, Yue, Miao, Zi-Yan, Su, Jian-Ping, Wasser, Samuel K., 2021. Shift of maternal gut microbiota of Tibetan antelope (Pantholops hodgsonii) during the periparturition period. Curr. Microbiol. 78 (2), 727-738. https://doi.org/10.1007/s00284-02002339-y.
Shideler, S.E., Savage, A., Ortuno, A.M., Moorman, E.A., Lasley, B.L., 1993. Monitoring female reproductive function by measurement of fecal estrogen and progesterone metabolites in the white-faced saki (Pithecia pithecia). Am. J. Primatol. 32 (2), 95-108. https://doi.org/10.1002/(ISSN)1098-234510.1002/ajp.v32:210.1002/ ajp. 1350320203.

Short, R.V., 1958. Progesterone in blood. II. Progesterone in the peripheral blood of pregnant cows. J. Endocrinol. 16, 426-428. https://doi.org/10.1677/joe.0.0160426.

Smyser, T.J., 2008. Population productivity and pronghorn nutrition during lactation. Proc. Bien. Pronghorn Workshop 23, 127-144.

Spencer, T.E., Bazer, F.W., 2004. Conceptus signals for establishment and maintenance of pregnancy. Reprod. Biol. Endocrinol. 2, 49. https://doi.org/10.1186/1477-7827-249.

Stabenfeldt, GH, Osburn, BI, Ewing, LL, 1970. Peripheral plasma progesterone levels in the cow during pregnancy and parturition. Am. J. Physiol. 218 (2), 571-575. https://doi.org/10.1152/ajplegacy.1970.218.2.571.

Stevenson, E.T., Gese, E.M., Neuman-Lee, L.A., French, S.S., 2020. Instability of glucocorticoid metabolites in coyote scats: implications for field sampling. HumanWildlife Interactions 14, 184-191. https://digitalcommons.usu.edu/cgi/viewconte nt. cgi? article $=1588 \&$ context $=$ hwi.

Stoops, M.A., Anderson, G.B., Lasley, B.L., Shideler, S.E., 1999. Use of fecal steroid metabolites to estimate the pregnancy rate of a free-ranging herd of Tule elk. J. Wildl. Manage. 63, 561-569. https://doi.org/10.2307/3802643.

Todd, Brian D., Rothermel, Betsie B., 2006. Assessing quality of clearcut habitats for amphibians: effects on abundances versus vital rates in the southern toad (Bufo terrestris). Biol. Conserv. 133 (2), 178-185. https://doi.org/10.1016/j. biocon.2006.06.003.

Touma, C., Palme, R., 2005. Measuring fecal glucocorticoid metabolites in mammals and birds: the importance of validation. Ann. N. Y. Acad. Sci. 1046, 54-74. https://doi. org/10.1196/annals.1343.006.

Vynne, C., Baker, M.R., Breuer, Z.K., Wasser, S.K., Reed, David, 2011. Factors influencing degradation of DNA and hormones in maned wolf scat. Anim. Conserv. 15 (2), 184-194. https://doi.org/10.1111/j.1469-1795.2011.00503.x.

Washburn, Brian E, Millspaugh, Joshua J, 2002. Effects of simulated environmental conditions on glucocorticoid metabolite measurements in white-tailed deer feces. Gen. Comp. Endocinol. 127 (3), 217-222. https://doi.org/10.1016/S0016-6480(02) 00056-4.

Wasser, S.K., Risler, L., Steiner, R., 1988. Excreted steroids in primate feces over the menstrual cycle and pregnancy. Biol. Reprod. 39, 862-872. https://doi.org/ 10.1095/biolreprod39.4.862.

Weber, B.J., Wolfe, M.L., White, G.C., 1982. Use of serum progesterone levels to detect pregnancy in elk. J. Wildl. Manage. 46, 835-838. https://doi.org/10.2307/3808587.

Welsh, T.H., Johnson, B.H., 1981. Stress-induced alterations in secretion of corticosteroids, progestins, luteinizing hormone and testosterone in bulls. Endocrinol. 109, 185-190. https://doi.org/10.1210/endo-109-1-185.

White, P.J., Garrott, Robert A., Kirkpatrick, Jay F., Berkeley, Elizabeth V., 1995. Diagnosing pregnancy in free-ranging elk using fecal steroid metabolites. J. Wildl. Dis. 31 (4), 514-522. https://doi.org/10.7589/0090-3558-31.4.514.

Wingfield, J.C., Sapolsky, R.M., 2003. Reproduction and resistance to stress: when and how. J. Neuroendocrinol. 15, 711-724. https://doi.org/10.1046/j.13652826.2003.01033.x.

Wislocki, G.B., Fawcett, D.W., 1949. The placentation of the pronghorned antelope (Antilocapra americana). Bull. Mus. Comp. Zool. 101, 548-558.

Woodruff, Susannah P., Adams, Jennifer R., Johnson, Timothy R., Waits, Lisette P., 2014. Rapid species identification of Sonoran pronghorn from fecal pellet DNA. Wildl. Soc. Bull. 38 (4), 842-848. https://doi.org/10.1002/wsb:477.

Woodruff, Susannah P., Johnson, Timothy R., Waits, Lisette P., 2016. Examining the use of fecal pellet morphometry to differentiate age classes in Sonoran pronghorn. Wildl. Biol. 22 (5), 217-227. https://doi.org/10.2981/wlb.00209.

Yoakum, J.D., 2004. Distribution and Abundance. In: O'Gara, B.W., Yoakum, J.D. (Eds.), Pronghorn: Ecology and Management. University Press of Colorado, Colorado, pp. 75-105. 